\title{
DESIGN AND DEVELOPMENT OF CONTEXT-AWARE RECOMMENDATION STRATEGY FOR E-LEARNING
}

\author{
SHAINA RAZA ${ }^{1}$, SYED RAZA BASHIR ${ }^{2}$, MUHAMMAD TAHIR HAMEED $^{3}$, MUHAMMAD JAWWAD ZAHEER ${ }^{4}$ \\ ${ }^{1}$ Faculty of Information Technology, University of Central Punjab (UCP) \\ ${ }^{2}$ Department of Computer Science \& Engineering, University of Engineering and Technology (UET), Lahore \\ ${ }^{3}$ Department of Mathematics, Lahore Garrison University (LGU), Lahore \\ ${ }^{4}$ Department of Computer Science \& Engineering, University of Engineering and Technology (UET), Lahore \\ \{shainaqamar, razabashir55\}@ hotmail.com, \{Tahirhameedch1,mjawwadzaheer\}@gmail.com
}

\begin{abstract}
Revised August 2015
Abstract: The practice of retrieving and recommending Learning Objects (LOs) to the learners according to their specific needs and requirements has been a very active research area in e-learning. This paper proposes the design and development of a context-aware methodology that comprises a Learning Object Repository (LOR), context-aware recommendation engine and a user-friendly interface. The existing approaches in this regard focus on learners' ratings, history, behavior and interests, rather ignored the knowledge gain and learning outcomes by the learners. The paper contributes in the research in threefold manner. First, a comparative survey of existing research in this area is presented. Secondly, the design and development of context-aware methodology for recommending LOs to the learners is proposed. Third contribution of the research is a mapping algorithm. Finally, it provides directions for the future research in this area.

Keywords: Learning Object Repository (L.O.R); Learning Object Metadata (L.O.M); Learning Object(LO); Recommender System( RS); E-learning; Technology Enhanced Learning (TEL)
\end{abstract}

1. Introduction. E-learning (or electronic learning) refers to the provision of education, learning or instructional program through electronic technology [8]. In web-based learning, learners and instructors are not bound to space, time and distance; and the gap between them is bridged with the practice of online technologies. Each content item in e-learning domain is called Learning Object (LO) and more formally defined as " any entity , digital or non-digital that may be used for learning, education and training", as per IEEE 1484.12.1-2002 LTSC definition[25]. LOs are composed of learning content and metadata (data about data). Learning Object Metadata (LOM) is a data model that consists of a hierarchy of data elements and is used to define a LO [23].

LOM enables exploring and cataloguing of LOs within shared digital repositories. Learning Object Repository (LOR) is a "digital repository that enables access to learning objects at local or distributed level" [45].

The strength of e-learning domain is reusability and interoperability. It requires assembling the chunks of learning from the open web and making them interoperable, reusable and sharable. However the issue in traditional e-learning systems is that the leaners are confronted with bulk of learning material, most of which consists of irrelevant materials and therefore hinders the learning process. Personalization in e-learning is solution to this problem. Personalization allows individualization of interaction between system and the learner based on learners' personal requirements and preferences and helps them shape their own learning paths (Jain, 2011). Personalization can be achieved by using Recommender System (RS).

A recommender system can be defined as an information filtering system which predicts users' preferences for a particular item [43]. RS in e-learning differs from those of social networks in that pedagogical items or LOs 
are recommended to the learners (consumers) based on their characteristics and attributes. Things that interests learners may not be pedagogically appropriate for them therefore e-learning RS consider not only learners' interests but also their assessment mechanism. For example, there is no sense of recommending a technical paper to a first semester undergraduate student or a popular magazine to a $\mathrm{PhD}$ student. Unlike RS in e-commerce, it is very important to keep a pedagogically ordered list of recommendations because the decision of making the best choice cannot be left at learner's end.

The concept of context in RS is gaining popularity in E-learning initiatives and can be more formally defined as "any information that features the situation of an entity" [1]. Therefore, a new RS i.e. Context-Aware Recommender Systems (CARS) has evolved recently to demonstrate the potential contextual recommendations in web-based learning [55]. This paper presents a context-aware recommendation strategy to make intelligent recommendations to the learners based on their characteristics with particular focus on assessment parameter.

2. Background. E-learning initiatives invested much in terms of budget, technology, software certificates, content development, content delivery, setup, teaching strategies, training, practices and maintenances to provide a replacement to traditional classroom system [8]. Despite all these efforts, the dropdown ratio of e-learning is much higher as compared to traditional system. The major loopholes in typical e-learning systems are as:

i. LORs in typical e-learning systems are static i.e. learning content has to be pre- loaded in them .

ii. Attempting to load LORs dynamically from open web will create overwhelmingly huge storage with limitless choices

iii. The system suffers from the inability to satisfy heterogeneous pedagogical needs of the learners. One of the possible solutions to aforementioned problems is to make use of RS.A survey on types of recommender systems is summarized as in table 1 :

\begin{tabular}{|c|c|c|c|}
\hline RS & Definition & Advantage & Disadvantage \\
\hline $\begin{array}{l}\text { Collaborative } \\
\text { filtering (CF) } \\
\quad(\text { Goldberg,1992) }\end{array}$ & $\begin{array}{l}\text { make assumptions based } \\
\text { on collaborative past } \\
\text { ratings of similar users }\end{array}$ & $\begin{array}{l}\text { No need to analyze } \\
\text { content to make } \\
\text { suggestions. } \\
\text { Recommendations } \\
\text { can be pre-computed in } \\
\text { advance }\end{array}$ & $\begin{array}{l}\text { Cold start(requires } \\
\text { abundant data to } \\
\text { recommend) } \\
\text { Sparsity (majority of } \\
\text { items are never rated) } \\
\text { Ramp up problem: } \\
\text { needs sufficient number } \\
\text { of users and ratings. }\end{array}$ \\
\hline $\begin{array}{l}\text { Content based } \\
\text { (CBF) (Pazzani \& } \\
\text { Bilsus 1997,Basu,1998) }\end{array}$ & $\begin{array}{l}\text { Assumptions are based on } \\
\text { the similar content } \\
\text { properties between an item } \\
\text { and a user's profile }\end{array}$ & $\begin{array}{ll}\text { Independent } & \text { of } \text { other } \\
\text { users } & \\
\quad \text { No } & \text { first-rater } \\
\text { problem } & \\
\end{array}$ & $\begin{array}{l}\text { Content analysis is } \\
\text { limited } \\
\text { New user problem }\end{array}$ \\
\hline $\begin{array}{l}\text { Context-aware } \\
\text { (Adomavicius ,2011) }\end{array}$ & $\begin{array}{l}\text { Recommendations are } \\
\text { based on the contextual } \\
\text { information ( time, space, } \\
\text { mood, } \\
\text { environment, system etc.) }\end{array}$ & $\begin{array}{l}\text { Can deploy other RS } \\
\text { approaches along with } \\
\text { context }\end{array}$ & $\begin{array}{l}\text { Incorporating context } \\
\text { is not a simple thing }\end{array}$ \\
\hline $\begin{array}{l}\text { Knowledge based } \\
\text { (Trewin \& Shari ,2000) }\end{array}$ & $\begin{array}{l}\text { Based on } \\
\begin{array}{l}\text { knowledge oxplicit } \\
\text { information, of }\end{array} \\
\text { user's } \\
\text { features and } \\
\text { contextual parameters to } \\
\text { generate reasoning to find } \\
\text { out which item meets } \\
\text { user's needs }\end{array}$ & $\begin{array}{l}\text { No ramp-up problem } \\
\text { Don't depend on } \\
\text { large statistics of data to } \\
\text { make suggestions }\end{array}$ & $\begin{array}{l}\text { Needs prior knowledge } \\
\text { of items and users's } \\
\text { needs }\end{array}$ \\
\hline $\begin{array}{l}\text { Demographic } \\
\text { (Krulwich 1997) }\end{array}$ & $\begin{array}{l}\text { Recommendations are } \\
\text { made on the personal data } \\
\text { (e.g. social statistics of } \\
\text { general population) and } \\
\text { items are classified into } \\
\text { user classes. }\end{array}$ & $\begin{array}{l}\text { No need of history of } \\
\text { ratings or prior } \\
\text { knowledge }\end{array}$ & $\begin{array}{l}\text { Limited accuracy } \\
\text { Needs textual reviews to } \\
\text { improve accuracy. }\end{array}$ \\
\hline
\end{tabular}




\begin{tabular}{|c|c|c|c|}
\hline $\begin{array}{l}\text { Constraint-based } \\
\text { (Felfernig ,2008) }\end{array}$ & \begin{tabular}{lr}
\multicolumn{2}{l}{ Recommendations } \\
bound to are \\
conditions
\end{tabular} & $\begin{array}{l}\text { Successful where items } \\
\text { are complex, } \\
\text { infrequently purchased } \\
\text { and many features are } \\
\text { not known to } \\
\text { customers. }\end{array}$ & $\begin{array}{l}\text { Often neglect } \\
\text { users'preferences }\end{array}$ \\
\hline $\begin{array}{l}\text { Hybrid } \\
\text { (Wang,2003) }\end{array}$ & $\begin{array}{l}\text { Combines a number of } \\
\text { techniques most popularly } \\
\text { CBF and CF }\end{array}$ & $\begin{array}{l}\text { Covers the } \\
\text { short-comings of one or } \\
\text { more techniques }\end{array}$ & Complex to design \\
\hline $\begin{array}{l}\text { Tag-aware } \\
\text { (Zhang, 2011) }\end{array}$ & $\begin{array}{l}\text { Recommends user tags to } \\
\text { assist in annotating items. }\end{array}$ & $\begin{array}{l}\text { Works well where } \\
\text { Timeliness is an issue }\end{array}$ & $\begin{array}{l}\text { 3-dimensional } \\
\text { recommendation function } \\
\text { needs to be reduced to } \\
\text { 2-Dimensional }\end{array}$ \\
\hline $\begin{array}{ll}\text { Time- } & \text { aware } \\
\text { (Campos,2014) }\end{array}$ & $\begin{array}{l}\text { Includes time dimension in } \\
\text { user-modelling and } \\
\text { recommendation function }\end{array}$ & $\begin{array}{l}\text { Time when user rated } \\
\text { the item is useful }\end{array}$ & $\begin{array}{l}\text { user-item rating } \\
\text { computational is costly }\end{array}$ \\
\hline $\begin{array}{l}\text { Federated RS } \\
\text { (L. Zhou ,2012) }\end{array}$ & $\begin{array}{lr}\text { rich set } & \text { of } \\
\text { recommendations that } \\
\text { depends on users' } \\
\text { interaction with distributed } \\
\text { environment and resources }\end{array}$ & $\begin{array}{l}\text { provides centralized } \\
\text { access point for } \\
\text { resources }\end{array}$ & \begin{tabular}{lr}
\multicolumn{1}{c}{ needs } & complex \\
algorithmic & approach to \\
efficiently & combine \\
different search results
\end{tabular} \\
\hline \begin{tabular}{lr}
\multicolumn{2}{l}{ Location-aware RS } \\
(Levandoski & 2012, \\
Symeonidis, & Ntempos \\
\& Manolopoulos,2014)
\end{tabular} & $\begin{array}{l}\text { uses spatial ratings to } \\
\text { produce recommendation } \\
\text { function }\end{array}$ & $\begin{array}{l}\text { these techniques are } \\
\text { scalable and efficient }\end{array}$ & $\begin{array}{l}\text { dependent on location } \\
\text { therefore future } \\
\text { predictions are not so } \\
\text { effective }\end{array}$ \\
\hline $\begin{array}{l}\text { Case-based } \\
\text { Reasoning(CBR) } \\
\text { (Derek ,2005) }\end{array}$ & $\begin{array}{l}\text { Make recommendations } \\
\text { by reusing the statistics of } \\
\text { similar and already } \\
\text { suggested products or } \\
\text { sample cases }\end{array}$ & $\begin{array}{l}\text { Ability to match } \\
\text { users' preferences in the } \\
\text { recommendation cycle } \\
\text { Recyle the process if } \\
\text { the user is not satisfied }\end{array}$ & $\begin{array}{l}\text { Which case is to be } \\
\text { selected is often unclear } \\
\text { and undefined }\end{array}$ \\
\hline $\begin{array}{l}\text { Semantic RS } \\
\text { (Peis,2008) }\end{array}$ & $\begin{array}{l}\text { Make use of knowledge } \\
\text { base that is usually defined } \\
\text { as ontology }\end{array}$ & $\begin{array}{l}\text { Promising in terms of } \\
\text { short-term and } \\
\text { mid-term results }\end{array}$ & $\begin{array}{l}\text { Needs support of a } \\
\text { number of supporting RS } \\
\text { techniques }\end{array}$ \\
\hline
\end{tabular}

Table 1: Types of Recommender Systems

Various applications of RS can be seen in e-commerce, web, travel, mobile phone technology, healthcare, TV, tourism, music, movies and many other fields. Majority of researchers have employed various techniques as mentioned in table 1 to propose different RSs. A number of diversified RSs are also implemented in e-learning. Tang \& Gordon [52] are reported to be the first ones to propose a smart adaptive RS for e-learning environment. Verbert[36] and Manouselis [35] presented a number of surveys on various RS in e-learning during the last decade. To summarize; a survey of various RS techniques in e-learning is given in table 2:

\begin{tabular}{l|ll} 
RS & Method applied \\
\hline Collaborative & $\bullet$ & memory-based [10]; [13]; [36] \\
filtering(CF) & $\bullet$ & association rule mining [60] \\
& $\bullet$ & Pearson-correlation based [10] \\
& $\bullet$ & user-based and item-based CF [54] \\
& $\bullet$ & multi-attribute CF algorithm[38] \\
& $\bullet$ & CF,tags,concept maps [26] \\
& \\
\hline
\end{tabular}




\begin{tabular}{|c|c|}
\hline $\begin{array}{l}\text { Content based } \\
\text { filtering (CBF) }\end{array}$ & $\begin{array}{ll} & \text { machine learning techniques [33] } \\
\text { - } & \text { Vector space model[21] } \\
\text { - } & \text { Vector space model[27] } \\
\end{array}$ \\
\hline Semantic based & $\begin{array}{l}\text { - } \begin{array}{l}\text { Ontology and knowledge base [42] } \\
\text { - }\end{array} \text { Personalized relevance measure, context aware recommendation, ontology based } \\
\text { with CF[11] } \\
\text { - Personalized hybrid RS,ontology,CF without rating[40] } \\
\text { - memory-based \& model-based CF, hybrid fuzzy-genetic approach[3] } \\
\text { - ontology, Singular Value Decomposition(SVD), data mining techniques[16] }\end{array}$ \\
\hline Hybrid filtering & $\begin{array}{ll}\text { - } & \text { CBF and CF,crawling and indexing techniques, Web usage mining techniques } \\
\text { (clustering and association rule mining)[27] } \\
\text { - } & \text { CBF,CF,attribute-based approach( [46][58] } \\
\text { - } & \text { Relational filtering,profile-based filtering,CF techniques [34] } \\
\text { - } & \text { matrix factorization techniques, user-to-user collaborative recommendation } \\
& \text { algorithm[12] }\end{array}$ \\
\hline $\begin{array}{l}\text { Personalized/Adap } \\
\text { tively }\end{array}$ & $\begin{array}{l}\text { - } \quad \text { probabilistic language modeling \& automatic text summarization techniques [59] } \\
\text { - } \\
\text { - } \\
\text { - } \\
\text { - } \\
\text { - }\end{array}$ \\
\hline data mining & $\begin{array}{l}\text { - Bayesian belief network (Kumar, 2005, p. 685-687) } \\
\text { - } \text { matriori prefix span algorithm ,Nearest neighborhood algorithm and preference } \\
\text { - Web mining approach[44] } \\
\text { - Empirical research using data mining methods and visualization tools[48] }\end{array}$ \\
\hline Context aware & $\begin{array}{l}\text { - } \quad \text { analysis of existing TEL RS and their possible dimensions[54] } \\
\text { - } \quad \text { Context-aware method, CF and association mining[56][39] } \\
\text { - }\end{array}$ \\
\hline
\end{tabular}

Table 2: Recommender Systems in e-learning

Problems with existing RS techniques in e-learning. The first group of related works discusses CF techniques which proved to be quite useful as it generates information by considering the suggestions of other related users. However it suffers from data sparsity and cold start problem i.e. insufficient new item's ratings [49].Verbert[36] applied CF algorithms to obtain learner's preferences in e-learning environment . The experimental study highlighted the data sparsity issue using this technique. The authors also recommended a solution to this issue that makes use of a collection of adequately massive datasets to capture learner's behavior. Data sparsity has also been pointed as a major problem in CF by Wen \& Wang [56] who proposed to use cosine similarity in replacement to inner product for sparse user/item matrix. Experiments by Wen [57] shows that there is no need of auxiliary dataset as is required by Verbet \& Duval[54] approach .But cosine similarity has the overhead of computing explicit score normalization [17]. However, RS in e-learning can benefit from multi-attribute CF algorithms as they are capable of parameterizing multiple rating data captured from numerous online portals[38]. But the multi-attribute $\mathrm{CF}$ is biased towards clustering users and resources and ignores the dissimilar characteristics of alike users which eventually lead to recommendation deviation [32].

The second group of related works is about content based RS that are implemented in e-learning. A key issue of CBF is over-specialization due to which only those items are recommended to the users that score high against user's profile. In general practice, items similar to those which have already been rated by the user should also be preferred [33]. Ghauth \& Abdullah [21] proposed a new e-learning RS that uses CBF technique, good learner's rating and pre-test to post-test to get feedback from the user. However the proposed methodology is prone to 'cold start' problem and the authors suggest using better approach in future. Khribi, Jemno and Nasraoui[27] proposed an automatic RS that uses learners' browsing histories and preferences . They used web usage mining techniques along with CFB and CF algorithms to make recommendations. The shortcoming in 
their proposed methodology is that there is need to improve the learner's model by including learners' preferences, pedagogical level and profiling information.

The third group of related works deals with semantic based RS in TEL. Semantic RS allows dynamic contextualization and limits the 'cold start' problems that are typical of other RS [40] however the approach is deficient in distribution environment and a generic domain. Cantador [11] presented a RS that uses CBF and CF models with addition to semantic context aware recommendation approach. Typically the recommendation engine doesn't take into account those news items that are related but not directly addressed by the profiles. The proposed approach makes use of ontology with additional weight concepts and the running context but rather ignored users' preferences. Nadolski [40] contributed by creating a simulation environment for informal learning networks in which he compared different variants of recommendation algorithms in a hybrid RS. The semantic approach is also used by Al-Shamri [3] and Cobos[16] together with multiple information retrieval techniques.

In addition to this, multiple RS are being proposed in e-learning that uses hybrid approach to recommendation algorithms. Khribi [27], Salehi [46] and Wen \& Fang [58] used hybrid version of CF and CBF approaches in their RS proposals but what is missing in the aforementioned models is the lack of ability to recommend appropriate learning content to the learners according to their learning outcomes. Menderia (2013) and Capuano [12] proposed integrating hybrid RS with e-learning environment however there is need to improve rating function to make better recommendations.

Personalization in e-learning involves learners' preferences; behavioral patterns and interests but often learner's ability and content difficulty are ignored. Chen [14][15] and Baylari [6] proposed personalization collaborated with item response theory to provide individual learning paths to the learners. Both systems emphasize on learner's ability but the latter one supersedes the former by incorporating learner's learning problems using artificial neural networks. MJ Huang [24] adds to the personalization research by employing genetic algorithm and case-based reasoning to provide individualized optimal learning paths. However limited research is available on such learning behaviors and learning activity patterns.

Knowledge Discovery and Data Mining (KDD) is the discipline that deals with the process of extracting knowledge from data. With the advent of e-learning, researchers begin investing various KDD methods to improve the underlying systems[44,46,48]. A hybrid approach (CBF and CF) proposed by Kumar [29] implements Markov model to evaluate qualitative LOs. The proposed approach differs from its contemporary ones in that it makes use of Bayesian Networks to compare the learning object quality reviews to overcome any deficiencies. Salehi [46] proposed a hybrid RS that implements sequential pattern mining approach and CBF methodology using Apriori and prefix span algorithms respectively. The proposed framework makes an attempt to discover latent patterns of the learning content particularly from the perspective of learners' attributes. As an extension to their previous research, Salehi [47] make use of weighed, cascaded and hybrid methods to generate recommendations. Comparative to other traditional RS algorithms, the results outperforms in terms of precision, recall and other evaluation metrics.

The literature shows that there are few CARS available for e-learning. Verbert [36], Manouselis [35] presented a survey of recent CARS that are being implemented in e-learning and therefore invites researchers to drive contextualization in e-learning. Henceforth, their research outlines future directions and challenges for the deployment and validation of CARS. It emphasizes that leaners' preferences are influenced by multi-dimensional contexts [51].Berri [7] contributes to contextualization by differentiating between technical (operational devices) and learners' (aims, goals ,background, assessment levels) context elements. Gallego [20] argues that LOs recommendations should be proactively pushed to the learners according to the context without their explicit feedback. Mayeku \&Betty [39] emphasized that human intelligence cannot be fully replaced by absolute machine control, therefore context-awareness can be used to support engaged learners' experience. Tang \& Gordan [52] being the first ones who proposed a RS for e-learning almost a decade ago, came with a newer proposal in the same field[51]. They argued that multi-dimensional recommendation function, though complex in nature produces better results on a diversified group of learners as compared to CF techniques. Thus, CARS seems to be most fruitful when it comes to effective personalization.

In this research, a context-aware recommendation methodology is proposed that is based on dynamic assessment mechanism and learners' feedback. Similar to previous related work, learners' preferences shall be considered foremost with the addition of their evaluation and assessment mechanism.

3. Proposed Methodology The proposed system consists of a database, recommendation and an interface layer. The database layer includes a LOR and their metadata record that suffices the purpose of retrieval, reusability, interoperability and sharing. Repository software can be created either by the instructional designers 
or they can use third party software to avail the educational economy. Taking inspiration from Biletskiy [9] for how to create a LOR, a crawler is used for massive downloading of LOs along with their metadata. In this case, Apache Nutch [4] is used to crawl on the web and Apache Solr for providing indexing. The middle layer is the recommendation layer that uses context-aware methodology to further improve, customize and rank search results from LOR. The RS layer explores its functionality through a Graphical User Interface (GUI) that allows an easy to use and interactive environment. A general description of the proposed framework is shown in the figure 1.

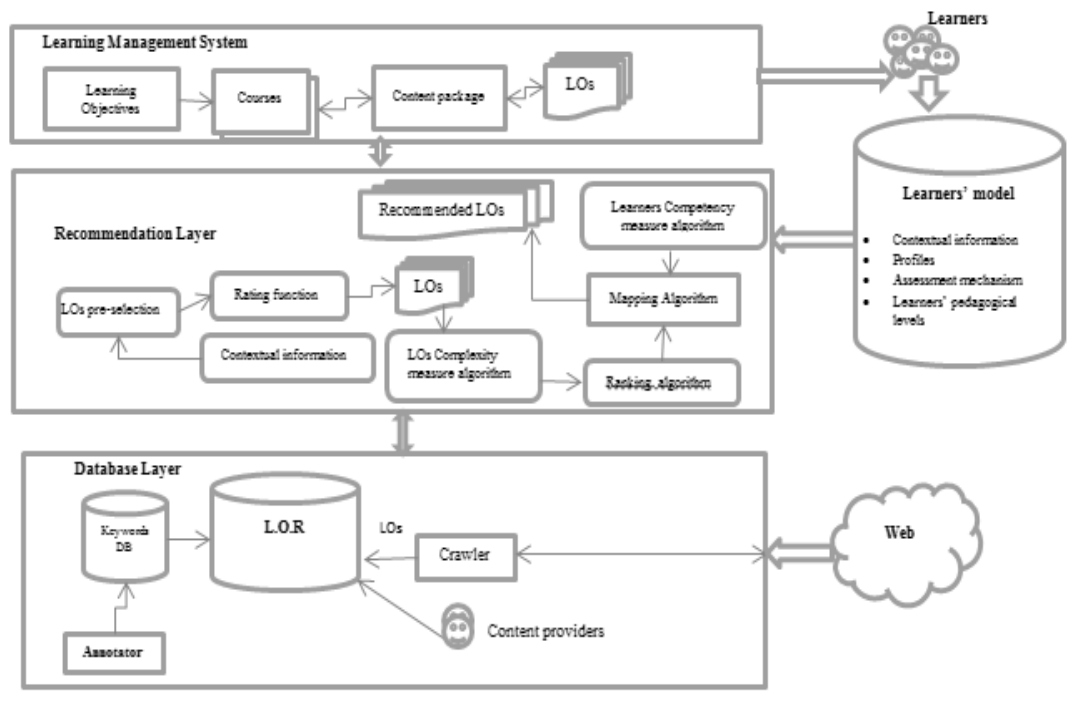

Figure 1: Overall Proposed System

\section{a. Context Aware Methodology for Recommendation of Learning Objects}

i. Context in RS in e-learning. The concept of 'context' in RS for e-learning differs substantially from other fields. Apart from generic factors such as location, time, environment, current activity etc., it also includes individualized learner's learning paths, collaborations, learning history, timing, moods and behavioral patterns [2]. This paper puts forward another important contextual element that is often ignored in education based RS i.e. assessment and evaluation mechanism pertaining to a particular learner.

ii. Initial Input. The model begins with the initial input of calculating main contextual values pertaining to the learners. Typically a recommendation function can be viewed as a prediction problem which takes as input user profile and a target item and predicts users' rating for that item [2]. The recommendation function is defined in equation 1 as:

\section{R: User x Items $\rightarrow$ Ratings (1)}

Unlike traditional models, CARS incorporates additional information to approximate users' preferences on unseen items. In e-learning, context-awareness provides more information about a learner in order to make more accurate and personalized recommendations. This leads to a multi-dimensional recommendation [2] function as shown in equation (2):

\section{$R:$ User $x$ Items $x$ Contexts $\rightarrow$ Ratings (2)}

Here 'contexts' represent consists of not only explicit users' preferences but also latent factors derived from the observations of users' actions and environment. 
iii. Representing and Modelling Context. There are three major approaches to obtain contextual information i.e. explicit, implicit or inferred from observed data [2]. Those contextual factors whose values are known at the time of recommendation are known as explicit factors (e.g. in case of purchase, when, where and with whom the purchase is made). Explicit information can be gathered either directly or through other elicitation means. Implicit contextual factors are those which are gathered from the observed data or the environment (e.g. spatial, temporal, surrounding etc.). Contextual information can also be inferred using statistical or predictive models (e.g. the frequency a user is changing the mode of his activity etc.). There exist two algorithmic paradigms to incorporate contextual information into RS [2]:

Contextual pre-filtering(PreF): contextual information is used in prior to filter out irrelevant ratings before computing recommendations

Contextual post-filtering (PoF): contextual information is used after the of application recommendation.

Given the learners' problem, the most suitable contextual approach would be PoF, since PreF method could narrow down the exact context in the proposed architecture. Another key issue is how to produce ratings i.e. explicitly or implicitly. Seeing the nature of the problem, implicit manner of getting ratings would be a better approach. A latent predictive model is to be used by RS to estimate unknown ratings and unobservable contextual variables.

iv. Evaluating Learning Material. The system also proposes a module that classifies LOs according to their difficulty index. The objective of this module is to find, quantify and rank document according to their complexity level. According to IEEE 1484.12.1 - 2002 standard, LOs are defined as "any reusable digital entities (audio ,video ,text ,image etc.) that may be used for learning, education and training" (IEEE LTSC) [25]. They need to be classified according to their difficulty index so that they can be later recommended to the leaners based on their evaluation. E.g. a learner that is classified as being "A" grader should be recommended those LOs whose difficulty index is highest or relatively higher. A simple approach to classify LOs for the proposed system is defined as in the subsequent sub-sections.

v. Annotation of Los. Extracting relevant metadata tag e.g. "Educational" element (IEEE LTSC) from Learning Objects Metadata (LOM) profile which are embedded with XML binding in LOR. This is useful method for both textual and non-textual LOs or part of them.

vi. Readability Index. Sometimes it becomes necessary to strictly find the exact difficulty index of a LO that majorly constitutes the textual data. The readability assessment metrics are therefore applied on such LOs. Here readability refers to the comprehensiveness and ease of the reading material. There is a number of readability metrics [18] proposed in the literature. They are being classified as being classical and modern The traditional readability metrics includes these famous formulae: Flesch Reading Ease formula, Flesch-Kincaid Grade Level, Fog Scale, SMOG Index, Coleman-Liau Index ,Automated Readability Index, Laesbarhedsindex, New Dale Chall, Powers-Sumner-Kearl Readability Formula, RIX, Kandel \& Moles[62]. The modern research in readability measures includes strain index(2007), McAlpine EFLAW (2004), Fernandez-Huerta measure (2008), Hayashi / Tateisi(1992), Douma, (1996), Lexile measure(2011), Coh-metrix indices (2010), DeLite system for German (2006),Gulpease Index (1988), Degrees of Reading Power (DRP) (1981)and naïve bayes[62].

vii. Evaluating Learners. Students are being assessed on different levels e.g. advanced, mediocre and beginners. A number of instruments are used to assess their competency e.g. Class tests, Moderated Discussion Boards(MDBs),examination ,experimental exercises, analysis of videotaped interviews ,tutorial problems, simulation exercises ,essay questions, GPA, help-seeking and other behavior. Learners are assessed by conducting pre-tests (two-tailed) to post-tests (one-tailed) in the learning environment.

viii. Mapping Algorithm. An important algorithm in this paper is to map clusters of LOs, categorized according to their complexity level, to the clusters of learners, grouped according to their competency levels. Therefore a mapping function is designed that has the following set of steps: 


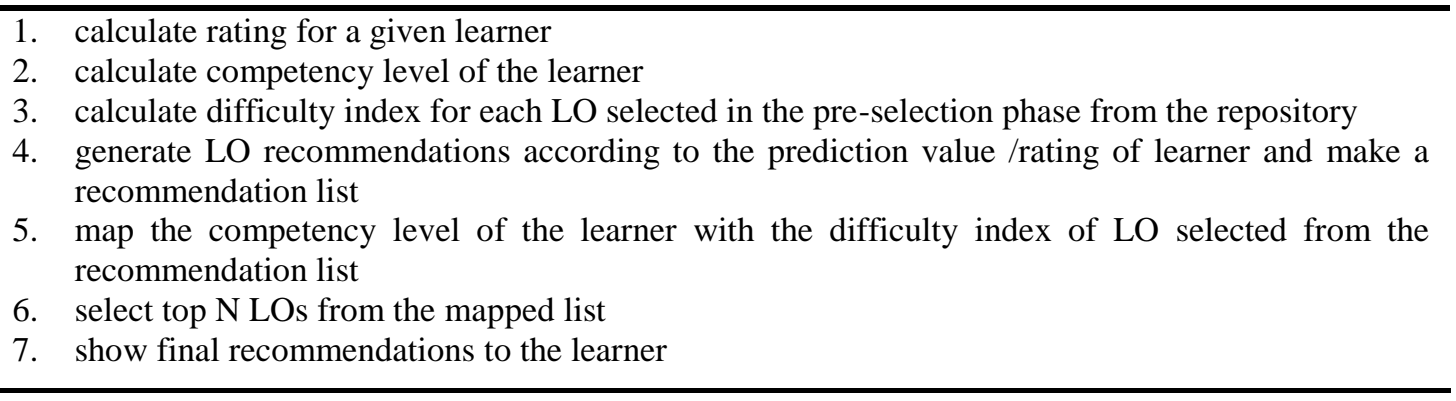

4. Conclusion. This paper presents a context-aware methodology to be implemented in the e-learning environment. A distinctive feature of this proposal is that it takes into account learners' assessment alongwith other contextual attributes pertaining to the learner. Mapping learners' competency level with the classified LOs is a key challenge to be met in this study. In short, this proposal outlines a number of key ideas that need to be explored for the purpose of sufficing the e-learning environment in real sense. In future, an extensive survey of Top-N algorithms will be studied to implement a suitable variant during the Pref phase in the recommendation function.

\section{REFERENCES}

[1] Abowd, G. D., Dey, A. K., Brown, P. J., Davies, N., Smith, M., \& Steggles, P. (1999, January). Towards a better understanding of context and context-awareness. In Handheld and ubiquitous computing (pp. 304-307). Springer Berlin Heidelberg.

[2] Adomavicius, G., \& Tuzhilin, A. (2011). Context-aware recommender systems. In Recommender systems handbook (pp. 217-253). Springer US.

[3] Al-Shamri, M. Y. H., \& Bharadwaj, K. K. (2008). Fuzzy-genetic approach to recommender systems based on a novel hybrid user model. Expert systems with applications, 35(3), 1386-1399.

[4] Apache Nutch. "Nutch Tutorial", http://wiki.apache.org/nutch/NutchTutorial

[5] Basu, C., Hirsh, H., \& Cohen, W. (1998, July). Recommendation as classification: Using social and content-based information in recommendation. In AAAI/IAAI (pp. 714-720).

[6] Baylari, A., \& Montazer, G. A. (2009). Design a personalized e-learning system based on item response theory and artificial neural network approach. Expert Systems with Applications, 36(4), 8013-8021.

[7] Berri, J., Benlamri, R., \& Atif, Y. (2006, July). Ontology-based framework for context-aware mobile learning. In Proceedings of the 2006 international conference on Wireless communications and mobile computing (pp. 1307-1310). ACM.

[8] Bhuasiri, W., Xaymoungkhoun, O., Zo, H., Rho, J. J., \& Ciganek, A. P. (2012). Critical success factors for e-learning in developing countries: A comparative analysis between ICT experts and faculty. Computers \& Education, 58(2), 843-855.

[9] Biletskiy, Y., Wojcenovic, M., \& Baghi, H. (2009). Focused crawling for downloading learning objects. Interdisciplinary Journal of E-Learning and Learning Objects, 5(1), 169-180.

[10] Bobadilla, JesúS, Fernando Ortega, Antonio Hernando, and JesúS Bernal, "A collaborative filtering approach to mitigate the new user cold start problem.", Knowledge-Based Systems 26 ,2012,pp. 225-238.

[11] Cantador, I., Bellogín, A., \& Castells, P. (2008, December). Ontology-based personalised and context-aware recommendations of news items. InProceedings of the 2008 IEEE/WIC/ACM International Conference on Web Intelligence and Intelligent Agent Technology-Volume 01 (pp. 562-565). IEEE Computer Society.

[12] Capuano, N., Iannone, R., Gaeta, M., Miranda, S., Ritrovato, P., \& Salerno, S. (2013). A Recommender System for Learning Goals. In Information Systems, E-learning, and Knowledge Management Research (pp. 515-521). Springer Berlin Heidelberg.

[13] Cechinel, C., Sicilia, M. Á., SáNchez-Alonso, S., \& GarcíA-Barriocanal, E. (2013). Evaluating collaborative filtering recommendations inside large learning object repositories. Information Processing \& Management, 49(1), 34-50.

[14] Chen, C. M., Lee, H. M., \& Chen, Y. H. (2005). Personalized e-learning system using item response theory. Computers \& Education, 44(3), 237-255. 
[15] Chen, C. M., Duh, L. J., \& Liu, C. Y. (2004, March). A personalized courseware recommendation system based on fuzzy item response theory. In e-Technology, e-Commerce and e-Service, 2004. EEE'04. 2004 IEEE International Conference on (pp. 305-308). IEEE.

[16] Cobos, C., Rodriguez, O., Rivera, J., Betancourt, J., Mendoza, M., LeóN, E., \& Herrera-Viedma, E. (2013). A hybrid system of pedagogical pattern recommendations based on singular value decomposition and variable data attributes. Information Processing \& Management, 49(3), 607-625.

[17] Dehak, N., Dehak, R., Glass, J. R., Reynolds, D. A., \& Kenny, P. (2010, June). Cosine Similarity Scoring without Score Normalization Techniques. In Odyssey (p. 15).

[18] Falchikov, N., \& Goldfinch, J. (2000). Student peer assessment in higher education: A meta-analysis comparing peer and teacher marks. Review of educational research, 70(3), 287-322.

[19] Felfernig, A., \& Burke, R. (2008, August). Constraint-based recommender systems: technologies and research issues. In Proceedings of the 10th international conference on Electronic commerce (p. 3). ACM.

[20] Gallego, D., Barra, E., Aguirre, S., \& Huecas, G. (2012, October). A model for generating proactive context-aware recommendations in e-learning systems. InFrontiers in Education Conference (FIE), 2012 (pp. 1-6). IEEE.

[21] Ghauth, K. I., \& Abdullah, N. A. (2010). Measuring learner's performance in e-learning recommender systems. Australasian Journal of Educational Technology, 26(6), 764-774.

[22] Goldberg, D., Nichols, D., Oki, B. M., \& Terry, D. (1992). Using collaborative filtering to weave an information tapestry. Communications of the ACM, 35(12), 61-70.

[23] Hodgins,Duval, Sutton \& Weibel. (2002). Metadata principles and practicalities. D-lib Magazine, 8(4), 16.

[24] Huang, M. J., Huang, H. S., \& Chen, M. Y. (2007). Constructing a personalized e-learning system based on genetic algorithm and case-based reasoning approach. Expert Systems with Applications, 33(3), 551-564.

[25] IEEE Learning Technology Standards Committee. "Draft standard for learning object metadata (IEEE 1484.12. 1-2002)." <http://ltsc. ieee. org/wg12/files/LOM_1484_12_1_v1_Final_Draft. pdf>. Acessado em 1, no. 05 (2002): 2011.

[26] Kardan, A., \& HENDIJANIFARD, F. (2011). Expert Finding System in E-Learning: Using Concept Maps.

[27] Khrib, M. K., Jemn, M., \& Nasraoui, O. (2008, July). Automatic recommendations for e-learning personalization based on web usage mining techniques and information retrieval. In Advanced Learning Technologies, 2008. ICALT'08. Eighth IEEE International Conference on (pp. 241-245). IEEE.

[28] Krulwich, B. (1997). Lifestyle finder: Intelligent user profiling using large-scale demographic data. AI magazine, 18(2), 37.

[29] Kumar, V., Nesbit, J., \& Han, K. (2005, July). Rating learning object quality with distributed bayesian belief networks: The why and the how. In Advanced Learning Technologies, 2005. ICALT 2005. Fifth IEEE International Conference on (pp. 685-687). IEEE.

[30] Levandoski, J. J., Sarwat, M., Eldawy, A., \& Mokbel, M. F. (2012, April). Lars: A location-aware recommender system. In Data Engineering (ICDE), 2012 IEEE 28th International Conference on (pp. 450-461). IEEE.

[31] Li, Y., Niu, Z., Chen, W., \& Zhang, W. (2011). Combining collaborative filtering and sequential pattern mining for recommendation in e-learning environment. InAdvances in Web-Based Learning-ICWL 2011 (pp. 305-313). Springer Berlin Heidelberg.

[32] Liu, K., Gulliver, S. R., Li, W., \& Yu, C. Service Science and Knowledge Innovation.

[33] Lops, P., De Gemmis, M., \& Semeraro, G. (2011). Content-based recommender systems: State of the art and trends. In Recommender systems handbook (pp. 73-105). Springer US.

[34] Madeira, F. M. C., Abreu, S., \& Quaresma, R. F. C. (2013). Hybrid Recommender Strategy in Learning: An Experimental Investigation. Social Technologies, 3(1), 7-24.

[35] Manouselis, N., Verbert, K., Ochoa, X., Wolpers, M., Drachsler, H., Bosnic, I., \& Duval, E. (2012). Context-aware recommender systems for learning: a survey and future challenges. Learning Technologies, IEEE Transactions on, 5(4), 318-335.

[36] Manouselis, Nikos, Hendrik Drachsler, Katrien Verbert, and Erik Duval, "Recommender systems for learning.", Springer Science \& Business Media, 2012.

[37] Manouselis, N., Drachsler, H., Verbert, K., \& Duval, E. (2012). Recommender systems for learning. Springer Science \& Business Media.

[38] Manouselis, N., Vuorikari, R., \& Van Assche, F. (2010). Collaborative recommendation of e-learning 
resources: an experimental investigation. Journal of Computer Assisted Learning, 26(4), 227-242.

[39] Mayeku, B. (2014, October). Enhancing personalization and learner engagement through context-aware recommendation in TEL. In Proceedings of the 8th ACM Conference on Recommender systems (pp. 413-415). ACM.

[40] Nadolski, R. J., Van den Berg, B., Berlanga, A. J., Drachsler, H., Hummel, H. G., Koper, R., \& Sloep, P. B. (2009). Simulating light-weight personalised recommender systems in learning networks: A case for pedagogy-oriented and rating-based hybrid recommendation strategies. Journal of Artificial Societies and Social Simulation, 12(1), 4.

[41] Pazzani, M. J., \& Billsus, D. (2007). Content-based recommendation systems. In The adaptive web (pp. 325-341). Springer Berlin Heidelberg.

[42] Peis, E., del Castillo, J. M., \& Delgado-López, J. A. (2008). Semantic recommender systems. analysis of the state of the topic. Hipertext. net, 6, 1-5.

[43] Ricci, F., Rokach, L., \& Shapira, B. (2011). Introduction to recommender systems handbook (pp. 1-35). Springer US.

[44] Romero, C., Espejo, P. G., Zafra, A., Romero, J. R., \& Ventura, S. (2013). Web usage mining for predicting final marks of students that use Moodle courses. Computer Applications in Engineering Education, 21(1), 135-146.

[45] Roy, D., Sarkar, S., \& Ghose, S. (2010). A comparative study of learning object metadata, learning material repositories, metadata annotation \& an automatic metadata annotation tool. Advances in Semantic Computing, 2, 103-126.

[46] Salehi, M., \& Kamalabadi, I. N. (2013). Hybrid recommendation approach for learning material based on sequential pattern of the accessed material and the learner's preference tree. Knowledge-Based Systems, 48, 57-69.

[47] Salehi, M., Pourzaferani, M., \& Razavi, S. A. (2013). Hybrid attribute-based recommender system for learning material using genetic algorithm and a multidimensional information model. Egyptian Informatics Journal, 14(1), 67-78.

[48] Shi, L., Cristea, A., Awan, M. S., Stewart, C., \& Hendrix, M. (2013). Towards understanding learning behavior patterns in social adaptive personalized e-learning systems.

[49] Shute, V., \& Towle, B. (2003). Adaptive e-learning. Educational Psychologist,38(2), 105-114.

[50] Symeonidis, P., Ntempos, D., \& Manolopoulos, Y. (2014). Recommender Systems for Location-based Social Networks. Springer.

[51] Tang, T. Y., Winoto, P., \& McCalla, G. (2014). Further thoughts on context-aware paper recommendations for education. In Recommender Systems for Technology Enhanced Learning (pp. 159-173). Springer New York.

[52] Tang, T. Y., \& McCalla, G. (2003, July). Smart recommendation for an evolving e-learning system. In Workshop on Technologies for Electronic Documents for Supporting Learning, International Conference on Artificial Intelligence in Education (AIED 2003).

[53] Trewin, S. (2000). Knowledge-based recommender systems. Encyclopedia of Library and Information Science: Volume 69-Supplement 32, 180.

[54] Verbert, K., Drachsler, H., Manouselis, N., Wolpers, M., Vuorikari, R., \& Duval, E. (2011, February). Dataset-driven research for improving recommender systems for learning. In Proceedings of the 1st International Conference on Learning Analytics and Knowledge (pp. 44-53). ACM.

[55] Wang, K., Gelgele, H. L., Wang, Y., Yuan, Q., \& Fang, M. (2003). A hybrid intelligent method for modelling the EDM process. International Journal of Machine Tools and Manufacture, 43(10), 995-999.

[56] Wang, S. L., \& Wu, C. Y. (2011). Application of context-aware and personalized recommendation to implement an adaptive ubiquitous learning system. Expert Systems with applications, 38(9), 10831-10838.

[57] Wen, H., Ding, G., Liu, C., \& Wang, J. (2014). Matrix Factorization Meets Cosine Similarity: Addressing Sparsity Problem in Collaborative Filtering Recommender System. In Web Technologies and Applications (pp. 306-317). Springer International Publishing.

[58] Wen, H., Fang, L., \& Guan, L. (2012). A hybrid approach for personalized recommendation of news on the Web. Expert Systems with Applications, 39(5), 5806-5814.

[59] Yang, G., Wen, D., Chen, N. S., \& Sutinen, E. (2012, July). Personalized Text Content Summarizer for Mobile Learning: An Automatic Text Summarization System with Relevance Based Language Model. In Technology for Education (T4E), 2012 IEEE Fourth International Conference on (pp. 90-97). IEEE. 
[60] Zaíane, O. R. (2002, December). Building a recommender agent for e-learning systems. In Computers in Education, 2002. Proceedings. International Conference on (pp. 55-59). IEEE.

[61] Zhou, L., El Helou, S., Moccozet, L., Opprecht, L., Benkacem, O., Salzmann, C., \& Gillet, D. (2012). A federated recommender system for online learning environments. In Advances in Web-Based Learning-ICWL 2012 (pp. 89-98). Springer Berlin Heidelberg.

[62] FREE READABILITY FORMULAS : FREE READABILITY TOOLS : READABILITY SOFTWARE. (N.D.). RETRIEVED DECEMBER 24, 2015, FROM HTTP://WWW.READABILITYFORMULAS.COM 